Corrigendum

\title{
Corrigendum to "Bionic Silk Fibroin Film Promotes Tenogenic Differentiation of Tendon Stem/Progenitor Cells by Activating Focal Adhesion Kinase"
}

\author{
Kang Lu $\mathbb{D}^{1},{ }^{1}$ Xiaodie Chen $\mathbb{D}^{2},{ }^{2}$ Hong Tang $\mathbb{D}^{1},{ }^{1}$ Mei Zhou $\mathbb{D},{ }^{1}$ Gang He $\mathbb{D}^{1},{ }^{1}$ Zhisong Lu $\mathbb{D},{ }^{2}$ \\ and Kanglai Tang $\mathbb{D}^{1}$ \\ ${ }^{1}$ Department of Orthopedics/Sports Medicine Center, State Key Laboratory of Trauma, Burn and Combined Injury, \\ Southwest Hospital, Army Medical University (Third Military Medical University), Chongqing 400038, China \\ ${ }^{2}$ Institute for Clean Energy \& Advanced Materials, School of Materials \& Energy, Southwest University, Chongqing 400715, China \\ Correspondence should be addressed to Zhisong Lu; zslu@swu.edu.cn and Kanglai Tang; tangkanglai@hotmail.com \\ Received 2 February 2021; Accepted 2 February 2021; Published 3 March 2021
}

Copyright (C) 2021 Kang Lu et al. This is an open access article distributed under the Creative Commons Attribution License, which permits unrestricted use, distribution, and reproduction in any medium, provided the original work is properly cited.

In the article titled "Bionic Silk Fibroin Film Promotes Tenogenic Differentiation of Tendon Stem/Progenitor Cells by Activating Focal Adhesion Kinase" [1], the authors identified that incorrect figures were included for Figures 3 and 4 due to a typesetting error. The authors confirm that this does not affect the results of the article, and the corrected Figures 3 and 4 are as follows: 


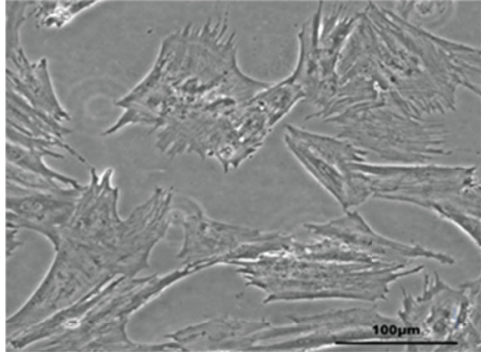

(A)

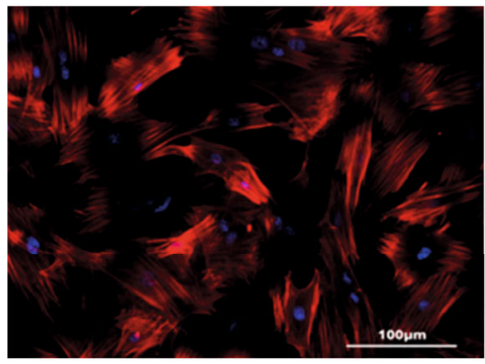

(D)
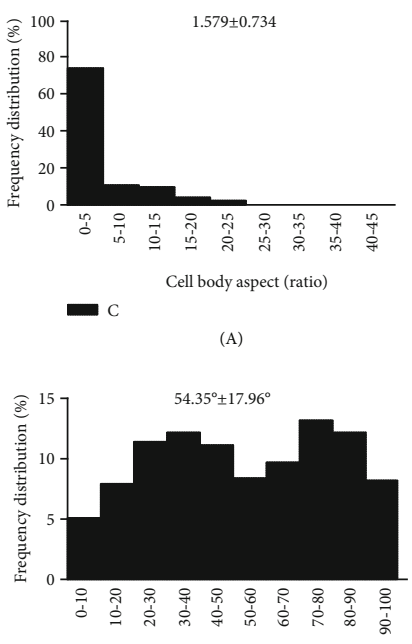

Cell body major axis angle (degree)

(E)

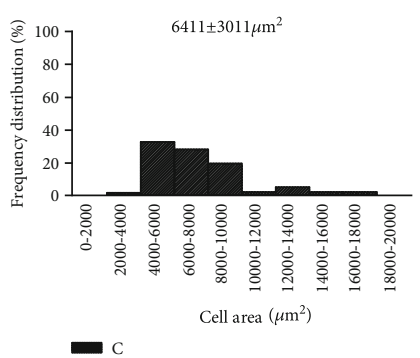

(I)

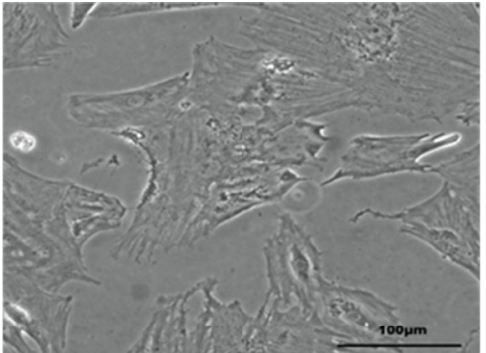

(B)

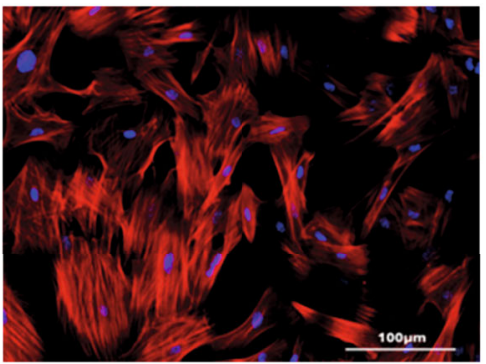

(E)

(a)

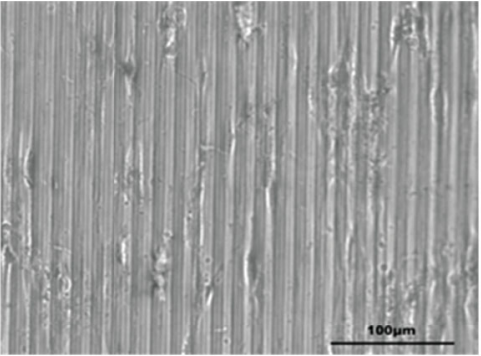

(C)

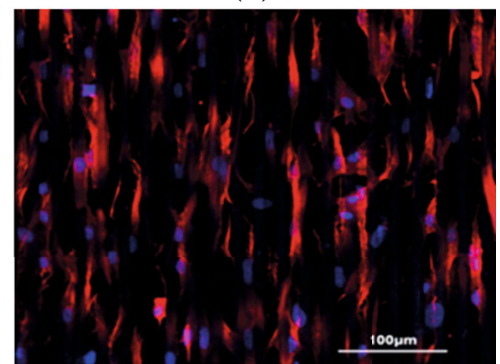

(F)
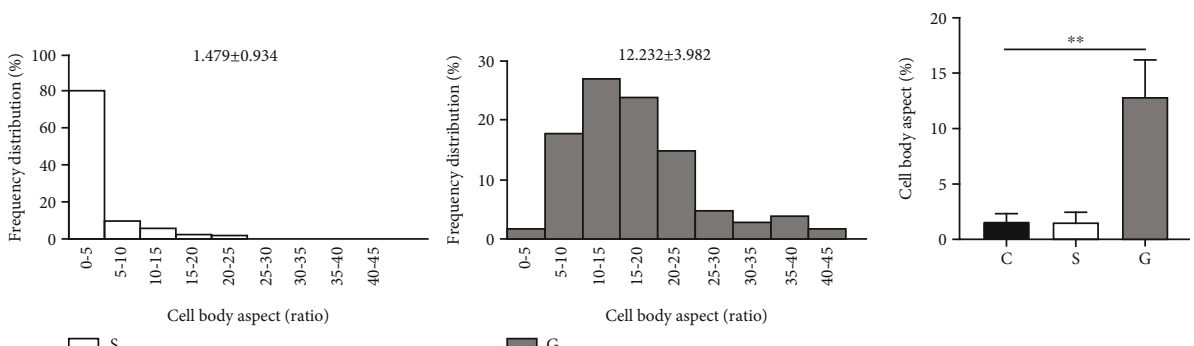

(B)
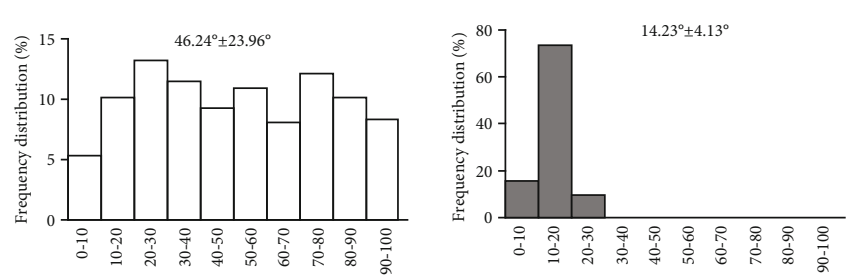

(D)

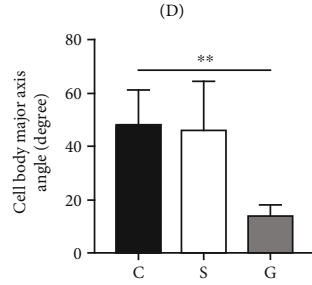

$\square \mathrm{G}$

(G)

(H)
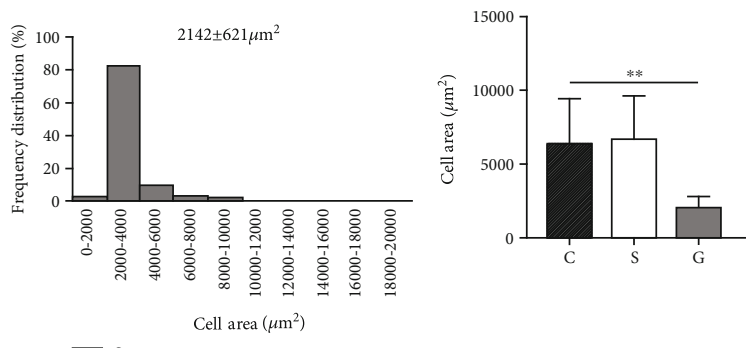

$\square s$

(b)

FIGURE 3: The cell morphology of TSPCs on different matrix surfaces. (a) Cell morphology observation: (A-C) cell morphology under a light microscope; (D-F) the morphology of TSPCs under a confocal laser scanning microscope. The nuclei were stained blue; the cytoskeletons were stained red; (A, D) TSPCs in the cell culture plate; (B, E) TSPCs on the smooth SF film; (C, F) TSPCs on the SF film with a microstructure. (b) Analysis of cell morphology: (A-D) cell body aspects; (E-H) cell body major axis angle (I-L) cell area; group C: TSPCs on the cell culture plate; group S: TSPCs on the smooth SF film; group G: TSPCs on the SF film with a microstructure; ${ }^{* *} P<0.01$. 


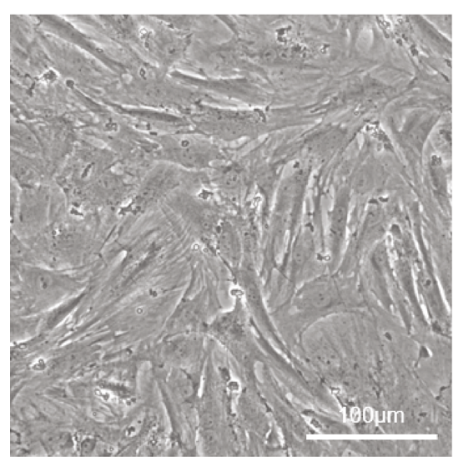

(A)

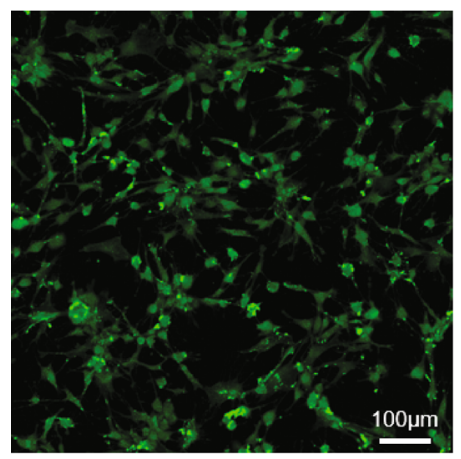

(D)

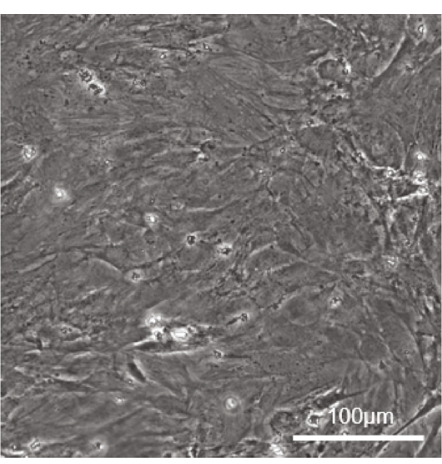

(B)

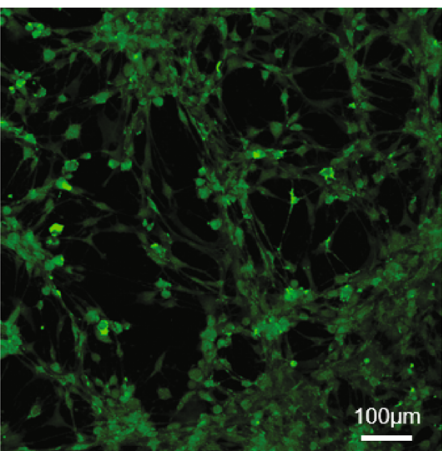

(E)

(a)

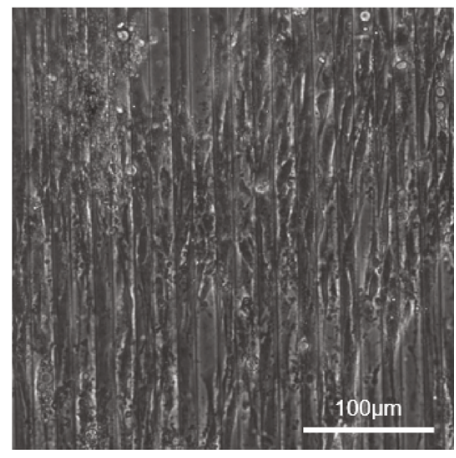

(C)

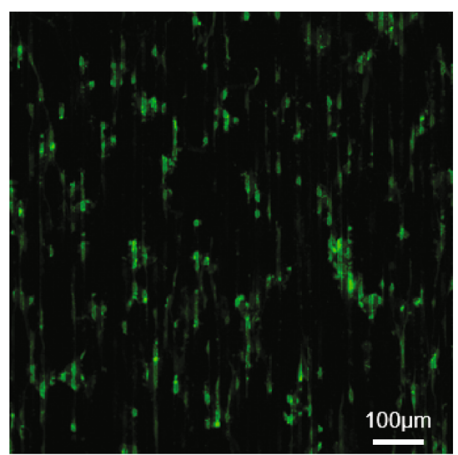

(F)

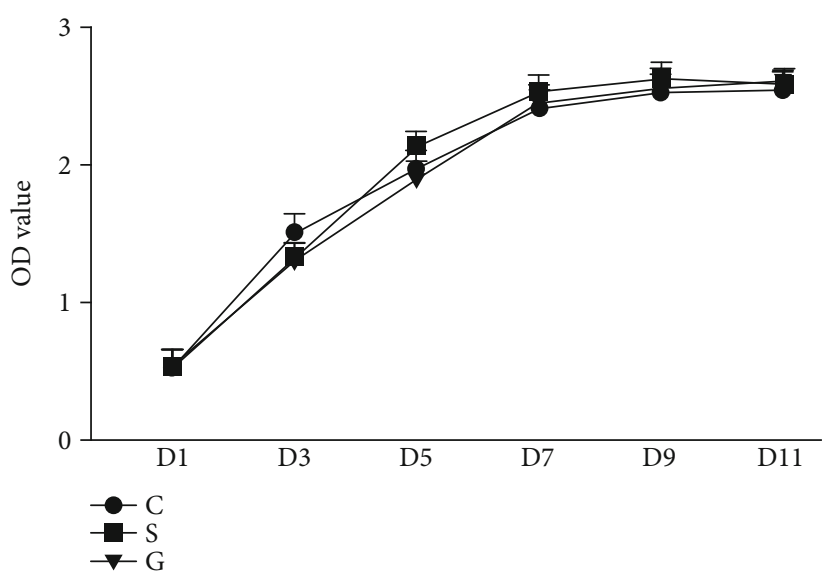

(b)

Figure 4: Live/dead cell staining and CCK-8 assay. (a) (A-C) Optical photomicrographs after TSPCs reached 90-100\% confluence; (D-F) live/dead staining of TSPCs on the tissue culture plate (D), SF film with a smooth surface (E), and SF film with microstructure (F). (b) The CCK-8 curve of the different groups; group C: TSPCs on the cell culture plate; group S: TSPCs on the smooth SF film; group G: TSPCs on the SF film with a microstructure.

\section{References}

[1] K. Lu, X. Chen, H. Tang et al., "Bionic silk fibroin film promotes tenogenic differentiation of tendon stem/progenitor cells by activating focal adhesion kinase," Stem Cells International, vol. 2020, Article ID 8857380, 10 pages, 2020. 